\title{
El maestro sabio o las treinta mil leyes de las cuatro estaciones (tercera parte)
}

\author{
José Luís Turabián Fernándeza y Benjamín Pérez Francob \\ Tutores de residentes de Medicina de Familia
}

\begin{abstract}
${ }^{\text {a }}$ Centro de Salud
"Santa M. ${ }^{\text {a }}$ de Benquerencia" de Toledo. Unidad Docente Multiprofesional de Atención Familiar y Comunitaria de Toledo.

${ }^{b}$ Centro de Salud

"Estación" de Talavera de la Reina. Unidad Docente Multiprofesional de Atención Familiar y Comunitaria de Talavera de la Reina (Toledo).
\end{abstract}

\begin{abstract}
RESUMEN
Esta es la tercera entrega de una serie de cuatro artículos muy especiales sobre la historia del maestro sabio, Gin y Seng, y su aprendiz de nombre cambiante. El maestro es el descubridor de un cierto número de Leyes Docentes Científicas de la Formación de Aprendices que han revolucionado el mundo educativo. Son las leyes que gobiernan el universo de la formación del aprendiz; son inalterables y válidas por sí mismas. Existen desde un tiempo sin comienzo. En una clara alegoría a la formación de los médicos internos residentes, los autores nos van describiendo las etapas por las que pasan los residentes, desde sus inicios titubeantes (primavera) hasta su actuación independiente (invierno), y nos dan las claves de lo que debe ser la labor de tutorización, desarrollando un completo curso de formación para tutores de residentes.
\end{abstract}

Palabras clave: Educación Médica. Tutorización. Docencia. Médico interno residente.

\section{ABSTRACT}

The wise master, or the thirty thousand laws of the four seasons (part three)

This is the third part of a series of four very special articles about the story of the wise master, Gin y Seng and his assistant, of changing name. The master is the discoverer of a certain number of Scientific Teaching Laws on Apprentice Training which have revolutionized the world of education. They are the laws which govern the apprentice's learning universe; they are inalterable and valid in their own right. They have existed for a time without beginning.

In a clear allegory of the training of Resident Medical Interns, the writers gradually describe the stages through which the residents go, from their hesitant beginnings (spring) to acting independently (winter) and we are given the keys to what must be the labour of tutoring, developing a complete training course for resident tutors.

Key words: Medical Education. Tutoring. Teaching. Resident medical intern.

\section{Capítulo 18. La formación del aprendiz: el otoño}

El crepúsculo, el declinar del sol. El Maestro Gin y Seng observa con su habitual brillo en los ojos la llegada del otoño. El año se acerca a su término y las lluvias terminan con el estío. Las hojas en los árboles amarillean, preparándose para el sueño invernal. La luz disminuye y la atención se dirige hacia dentro. Es momento de recogerse, revisar lo antiguo y prepararse para la renovación, desprendiéndose de lo que sobra o estorba. Cultivar la serenidad, aquietar las emociones... y observarlas, descubrir que son como el agua y pueden desbordarse como en las riadas, descargar la tensión como la lluvia que limpia el bochorno del viento del sur, estancarse como en las ciénagas... o serenarse como en un lago de montaña.

Durante el otoño muchas plantas maduran, lo que significa que alcanzan su máximo desarrollo. Los frutos del manzano crecen en las ramas y alcanzan mayor peso, por lo que es necesario recogerlas antes que caigan al suelo. Las bellotas se caen de los robles. Las hojas de muchas especies de árboles, que eran verdes, se tornan rojas, doradas, amarillas y marrones, y luego se caen del árbol. Al hacerse el clima más frío durante el otoño, muchos 
animales se preparan para los cambios que se avecinan. Las ardillas se alborotan recogiendo nueces y almacenándolas para los fríos meses venideros. Los osos comen todo lo que pueden para obtener una mayor reserva de grasa y buscan una guarida que los proteja del frío. Algunas especies de aves migran, realizando un largo viaje volando hacia el sur, donde el clima es más cálido. En los océanos, las grandes ballenas también migran hacia aguas más tibias.

-¡Ah, el tesoro del otoño! -suspira el Maestro Gin y Seng-. Es la época en que el aprendiz es adulto..., es la época de la paz y algún sosiego, es la época de la reflexión sobre la sabiduría. El otoño es también permitirse el descanso tras el esfuerzo; la recuperación tras la tensión, que se complementa con la relajación. Pero esa preparación para alcanzar el tesoro del otoño se debe hacer sin miedos, sin temores, sin pánico a lo inevitable; debe ser asimilada y asumida, con la sonrisa de la experiencia, con la piel curtida de haber soportado ya todos los soles y todos los aires, con la más plena y segura esperanza de un futuro.

Y escribe en un papel que luego coloca bien visible en la pared:

\section{¿Cómo encontrar el tesoro del otoño? Aplicando las leyes por mí descubiertas: \\ La Ley del Beagle \\ La Ley Robinson Crusoe \\ La Ley de Llanfairpwllgwyngyllgogerychwyrndro- bwlll lan-tysiliogogogoch}

La Ley de la Caja de Pañuelos

La Ley del Primer Toque

La Ley del Crecimiento por Analogía

La Ley del Periodista

\section{Capítulo 19. Ley del Beagle}

-Mira, querido aprendiz -que era ahora una fruta madura-, he preparado este Cuaderno o Diario para que lo usemos tú y yo -dijo el Maestro Gin y Seng-. Es fruto de mi último descubrimiento, la 'Ley del Beagle'. Podemos anotar los conceptos que vemos, los datos que nos llamaron la atención, los problemas vividos, el análisis de los mismos, las propuestas de formación. Será un diario de bitácora de nuestra travesía -añadió el Hechicero Docente.

-¿Beagle? -preguntó Fruta-Madura.

-Del "Viaje del Beagle" de Charles Darwin. Ya sabes, un cuaderno de viaje. El viaje que inició Darwin en 1831, que tenía que durar dos años y acabó cinco años después, el 2 de octubre de 1836, en Falmouth. Uno de los viajes más espectaculares de toda la historia, en el que, paralelamente al descubrimiento de paisajes exóticos, se llevó a cabo el viaje de investigación que acabó en la teoría de los orígenes de las especies, y los orígenes del hombre. Las islas de Cabo Verde, Brasil, Argentina, Tierra de Fuego, las islas Malvinas, los Andes, las islas Galápagos, Tahití, Nueva Zelanda, Australia, Mauricio, el Cabo de Buena Esperanza... Darwin tomó buena nota de lo que veía, de lo que intuía, de lo que ocurría y de lo que poco a poco se iba demostrando. En su cuaderno de viaje encontramos el recuento de los animales y las plantas que fueron objeto de examen y de investigación, igual que de los habitantes de lugares exóticos, de sus comportamientos, de los rasgos de su físico y de su carácter, de sus costumbres y modos de vida.

-Está bien. Comentamos muchos temas que surgen en las lecciones, y buscamos frecuentemente referencias, y realizamos reflexiones... -dijo FrutaMadura.

- ¿Te parece que, para empezar, vayas estos días anotando algún problema que tendrías ahora mismo para hacer la tarea tú sola y lo comentemos luego al final de la semana? -preguntó el Maestro Gin y Seng, y añadió-: Pues, ¿de qué sirve navegar sin una brújula ni un mapa?

-iAjá! Será como comenzar un álbum de fotos o simplemente la caja donde guardamos viejas fotografías, ¿no es cierto? -preguntó Fruta-Madura.

-Sí, eso es. Un día, nos dará por poner orden en las estanterías o en los armarios y en un momento u otro llegará a nuestras manos el álbum de fotografías; algunas serán recientes, pero otras serán de mucho tiempo atrás. Es un viaje como cualquier otro, con sus sorpresas... -sentenció el Maestro.

Y El Maestro Gin y Seng comenzó a meditar. «La elaboración de un diario de aprendizaje es una estrategia útil..., consiste en hacer que los alumnos lleven un diario de campo en el que registran las experiencias realizadas en clase, las dificultades experimentadas en los diversos temas o unidades 
didácticas, las concepciones iniciales y los procesos de cambio conceptual, junto con los resultados de los debates desarrollados en clase y de los intercambios de puntos de vista con los compañeros. En el diario se pueden anotar, asimismo, sus expectativas con los exámenes, los resultados obtenidos y las causas de las posibles discrepancias. De esta manera, a medida que se avanza en el desarrollo de las asignaturas, existe una base documental a la que se puede recurrir para fomentar la autoevaluación de sus avances en las asignaturas y del cambio en sus concepciones sobre el aprendizaje».

«Alcanzar una meta en sí mismo no tiene tanto valor como la experiencia que se puede adquirir en el proceso de solventar los obstáculos del camino. El proceso es más gratificador que la victoria en sí misma. Como al hacer el Camino de Santiago, donde puede ser más importante el propio camino que el llegar al final. Para el aprendiz es más importante avanzar con reflexión para cada contenido, que recorrer todos los contenidos del programa».

Y escribió en su pizarra:

Lo que yo digo no son meras palabras, sino referencias precisas de mi cuaderno de navegación

\section{Capítulo 20. Ley Robinson Crusoe}

- $\mathrm{iHe}$ descubierto una nueva Ley, que es continuación de la del Beagle, la 'Ley Robinson Crusoe'! -exclamó el Maestro Gin y Seng.

- ¿El de la isla desierta? -dijo, demostrando su cultura general, el aprendiz, que era ahora un tallo alto de trigo de color marrón seco.

-Efectivamente. Robinson Crusoe naufraga en una isla cercana a la desembocadura del río Orinoco. Es el único superviviente. Consigue armas y materiales del barco encallado, construye su propia choza y comienza un diario donde va reseñando sus avances en el trabajo de la madera, en el cultivo de cereal, en la doma de cabras y en la alfarería. Nosotros tenemos ya el diario, pero nos falta ir repasándolo para observar los cambios y aprendizajes -dijo el Maestro-. Es importante mantener una documentación sobre las tareas del estudiante, como el "diario de a bordo" de un barco, nos informará de dónde han venido, dónde están, y dónde irán. Este diario hay que mantenerlo y repasarlo. Nos ayudará a recordar eventos que no deberíamos olvidar, a reconocer patrones de comporta- miento, a mantener la continuidad y coherencia de la supervisión.

-Un diario es una herramienta poderosa para el crecimiento personal -prosiguió el Maestro-. Nos obliga a ser disciplinados y reflexivos. Nos dirá, como a Robinson Crusoe, si ha habido avances en el trabajo. Es un "catálogo del aprendizaje", una colección de evidencias sobre las experiencias de aprendizaje.

- ¿Repasamos entonces lo que llevamos anotado hasta ahora en el Cuaderno de Aprendizaje? -preguntó Tallo-Alto-De-Trigo-De-Color-Marrón.

-Sí, nos conviene repasar las acciones que pusimos en práctica después de decidirlas, pensar en las razones para no realizar las decisiones tomadas, los nuevos problemas formativos que han aparecido, la necesidad de nuevas acciones formativas... -contestó el Maestro Gin y Seng. Y añadió: Al repasar el Cuaderno de Aprendizaje, podemos constituir un nuevo instrumento para el aprendizaje: los "mapas conceptuales".

-Es lógico -dijo muy serio Tallo-Alto-De-Trigo-DeColor-Marrón-, teniendo en cuenta que el aprendizaje es un viaje..., necesitamos un mapa.

-Cierto. Como es sabido, los mapas conceptuales tienen por objeto representar relaciones entre conceptos en forma de proposiciones. Esas relaciones se representan mediante enlaces y ponen de manifiesto las dependencias, similitudes y diferencias entre conceptos, así como su organización jerárquica. El objetivo de este instrumento es favorecer el aprendizaje significativo y desarrollar el aprender a aprender. Los mapas conceptuales se pueden utilizar como instrumento diagnóstico, para explorar lo que los alumnos saben, para organizar secuencias de aprendizaje, para que éstos extraigan el significado de los libros de texto y para organizar y hacer explícita una secuencia de enseñanza. Además, los mapas conceptuales pueden utilizarse como guía para la preparación de trabajos escritos o como técnica de evaluación -explicó el Maestro.

-Creo que me resultará útil, ya que me ayudará a darme cuenta de mis procesos de aprendizaje y a valorar las relaciones entre conceptos, especialmente las relaciones cruzadas entre elementos que aparentemente están inconexos -dijo Tallo-AltoDe-Trigo-De-Color-Marrón, que era ya un aprendiz muy maduro.

El Maestro Gin y Seng se puso a meditar. Visualizaba mentalmente mapas y pensaba «su cerebro 
tiene muchos datos: "descárguelos" desarrollando un mapa mental»».

Y escribió en la pizarra:

Quince pasos más allá, quinientos pájaros azules vinieron volando, dibujaron tres veces un círculo a su alrededor y se marcharon volando

\section{Capítulo 21. Ley de Llanfairpwllgwyngyllgogery- chwyrndrobwl Illan- tysiliogogogoch}

El aprendiz, que era ya una hoja roja, dorada, amarilla y marrón, estaba anotando en su Cuaderno de Aprendizaje un nuevo problema que se le presentaba en su aprendizaje. El Maestro Gin y Seng, que le vio, le preguntó:

- ¿Has podido anotar algún nuevo problema en el Cuaderno de Aprendizaje, Hoja-Roja- DoradaAmarilla-Y-Marrón?

-¡Uf, un montón! -replicó este mientras resoplaba.

-Bueno, veamos alguno -propuso el Maestro.

-Quizás el principal es que no puedo separar los conceptos unos de otros, como vienen en los libros, sino que me parece que forman una maraña o red; no hay un nombre simple o un código individual para cada problema, el problema es un conjunto de problemas que toma una forma propia que es más y diferente que la suma de problemas individuales. No me queda más remedio que describir o narrar el problema, contarlo completamente, de seguido, casi sin respirar.

- ¡Bravo! Has descubierto tú sola la trascendental 'Ley de Llanfairpwillgwyngyllgogerychwyrndrobwlll lan- tysiliogogogoch'.

-¿Eh...? ¿Y cómo se pronuncia? ¿Cómo se dice...? -balbuceó Hoja-Roja-Dorada- Amarilla-Y-Marrón.

-Aunque unidos a Inglaterra desde el siglo XVI, Gales ha mantenido viva su entidad como nación, gracias, entre otras cosas, a su idioma endiablado. De las diversas lenguas de raíz celta, el galés es la más arcaica y enrevesada. Hay en la bahía de Tremadog un pueblecito que se llama Llanfairpwllgwyngyllgogerychwyrndrobwilllan- tysiliogogogoch, así, sin respirar, y que significa Santa María junto al álamo blanco del lago y San Tysilio de la cueva roja. Le pasa como a los problemas enmarañados en red que nos muestra la vida..., hay que entenderlos in- tegralmente, con toda su red entrelazada, y nombrarlos con palabras que se escriben todas seguidas -explicó el Maestro Gin y Seng.

-Pero, ¿cómo se pronuncia? ¿Cómo se dice...? insistió el aprendiz.

-Fácilmente, Llanfairpwllgwyngyllgogerychwyrndrobwllllantysiliogogogoch. ¿Entendido? -contestó el Maestro Gin y Seng.

La mente del Maestro Gin y Seng meditaba..., «es el conocimiento por la experiencia; podemos darnos cuenta cómo después de beber leche azucarada nuestro estómago se sacia; si comemos miel, nos sabe dulce, no salada. Este es el conocimiento basado en la experiencia. La misma conexión podemos hacerla respecto a nuestras emociones; si estamos enfadados con alguien y expresamos nuestra ira, crearemos sufrimiento a esa persona y a nosotros mismos».

«Por la experiencia sabemos que no podemos separar el problema de su vivencia y del contexto" -pensó el Maestro Gin y Seng, que escribió en su pizarra:

Es solo a través de la propia experiencia, como cada uno aprende a ver si se ha obtenido el fruto de una práctica particular

\section{Capítulo 22. Ley de la Caja de Pañuelos}

- Hoy vamos a comentar cómo va tu formación -le dijo una luminosa mañana otoñal el Maestro Gin y Seng a su aprendiz-. Eres ya una grulla que está a punto de migrar hacia el sur, es decir, un aprendiz ya adulto, en el otoño de su formación. Y por eso nos conviene hacer un poco de evaluación.

- ¿Puedes mencionar algún concepto que te haya impactado más de todos los que has aprendido en este tiempo? -preguntó el Maestro.

-Sí, maestro, que hay que tener siempre encima de la mesa una caja de pañuelos de papel -contestó muy seria Grulla-Que-Está-A-Punto-De-MigrarHacia-El-Sur.

-¡Perfecto! -exclamó el Maestro-. Has descubierto una nueva ley, la 'Ley de la Caja de Pañuelos'. ¿Puedes explicármela?

-Sí, claro. Si aprendí algo hasta ahora, fue que es muy importante tener una caja de pañuelos sobre la 
mesa... Es como dar permiso para llorar a quienes vienen a nosotros. Significa que son bienvenidas las emociones, que no hay barreras para la expresión de los sentimientos, que allí se admiten personas, seres humanos..., que a veces Iloran -explicó Grulla-Que-Está-A-Punto-De-Migrar-Hacia-El-Sur.

El Maestro Gin y Seng estaba otra vez meditando... $Y$ finalmente escribió en su pizarra:

Compartir los sentimientos y las emociones nos ayudará a comprender

\section{Capítulo 23. Ley del Primer Toque}

-Estimado Maestro Gin y Seng -dijo un día el aprendiz, que era ya una ballena que busca aguas más cálidas-, he aprendido muchas cosas aquí, y entre ellas la 'Ley Scout' que nos dice que hay que explorar el terreno con tranquilidad en vez de decidir de inmediato; que hay que recoger datos..., y encontrar sorpresas que dan grandes ventajas. Sin embargo, esto se contradice con el hecho de que veo que en muchas ocasiones usted, Maestro, resuelve problemas casi inmediatamente..., como en el mismo momento que aparece la incertidumbre por la puerta. ¿Cómo puede ser eso? ¿Acaso hay alguna magia que no me ha enseñado?

-¡Vaya!, querida Ballena-Que-Busca-Aguas-MásCálidas, es maravilloso... ¡has descubierto la 'Ley del Primer Toque'! -exclamó el Maestro Gin y Seng.

-¿El primer toque? -preguntó la aprendiz.

-Sí. Saber al primer toque o reconocimiento de patrones... Los grandes jugadores de fútbol poseen un excelente primer toque; si piensas y actúas con rapidez puedes llegar a desarmar a la mejor defensa del mundo con tu primer toque de balón. En la vida, la resolución de problemas al primer toque se produce por la suma de varios factores que permiten una toma rápida de decisiones en condiciones de incertidumbre. El reconocimiento de patrones, la repetición de patrones de comportamientos, de presentación de problemas y de soluciones realizadas en contextos similares. La continuidad de la reflexión y el conocimiento de los contextos donde ocurre el problema son herramientas que permiten la resolución de problemas al primer toque. Sin embargo, como en el fútbol, aunque el primer toque lo sea todo y consigas esa jugada, has de intentar mantener el balón. Controlar el balón quiere decir tomar posesión de él. Un jugador gana la posesión cuando se coloca o alinea con el balón para así maniobrar con éste. Recuerda, algunas veces un jugador puede distribuir o enviar el balón al primer toque, pero eso no es considerado control. Cuando hablamos de "control del equipo" nos referimos a la habilidad global de un grupo de jugadores para mantener la posesión del balón.

-Así, no es correcto concluir que jugar a un toque es siempre más efectivo que conservar el balón. En la práctica, será la situación la que debería indicar cuándo usar el control y cuándo jugar a un toque -concluyó el Maestro Gin y Seng.

Y mientras meditaba, escribió en la pizarra:

Un verso dura muy poco

\section{Capítulo 24. Ley del Crecimiento por Analogía}

El aprendiz, que era en este momento un álamo húmedo sin hojas junto al río, estaba atendiendo una lección... Mientras escuchaba el relato, se acordó de que, hacía unos meses, aprendió un concepto similar en otra lección, aunque en otro contexto diferente... Debido a ese aprendizaje pudo proponer una estrategia de actuación, con las oportunas similitudes y diferencias, en base al caso anterior.

El Maestro Gin y Seng, que le había visto actuar, le dijo al terminar:

-¡Muy bien!, Álamo-Húmedo-Sin-Hojas-Junto-AlRío, hemos descubierto otra Ley crucial: La 'Ley del Crecimiento por Analogía'.

-La casa de Neruda en Isla Negra fue hecha según una arquitectura orgánica, irregular, con mucha madera y anchos ventanales. No era racionalista, sino que estaba concebida como una segunda piel del morador. Como toda buena arquitectura, fue tomando forma sin ningún plan preconcebido, solo a golpes de intuición y de sueños. Y es que Neruda, como las gentes del pueblo, funcionan del mismo modo que la naturaleza: creciendo desde el interior hacia el exterior, creando estructuras -sean casas, pinturas o poemas- en base a una cierta ordenación de la analogía de las formas -explicó el Maestro.

-Y continuó: El crecimiento personal y profesional o el aprendizaje es una forma de mirar al futuro. $Y$ podemos crecer hacia el futuro de varias formas: el crecimiento normativo o racionalista -el futuro deseable que se diseña como un objeto, en base a un protocolo, como si cada hecho fuera nuevo y aislado- o por analogía con otros modelos de la 
naturaleza. El razonamiento analógico es un proceso de aprendizaje constructivo y dinámico para la adquisición de nuevos conocimientos, contrapuesto al aprendizaje repetitivo, memorístico o mecánico. La utilización de analogías es un mecanismo de aprendizaje que se basa en la transferencia del conocimiento a situaciones nuevas.

-La solución de problemas por analogía -siguió diciendo- supone un ejemplo de comparación selectiva, la persona que actúa se da cuenta de que esa información nueva se parece en varios aspectos -y difiere en otros- a la información ya conocida y utiliza dicha información de manera más adecuada para comprender la información nueva. Por ejemplo, un hechicero perspicaz relacionará un caso actual con los precedentes anteriores, o un abogado con los precedentes jurídicos anteriores.

El Maestro pareció entrar en trance. Nuevamente meditaba... «las analogías como anzuelos..., al considerar un tema y compararlo con "algo", ese "algo" se convierte en un anzuelo. Las analogías activan la creatividad, ya que ayudan a explicar, comprender, guiar y dirigir nuestro pensamiento».

Enseñar cuidadosamente, de forma secuencial, y con precisión, para evitar olvidar partes de las enseñanzas -escribió el Maestro Gin y Seng en su pizarra.

\section{Capítulo 25. Ley del Periodista}

El Maestro Gin y Seng preguntaba a su aprendiz, parecida ahora a la luz del sol de otoño que dora los membrillos:

- ¿En qué eran diferentes los dos últimos conceptos? ¿Cuáles crees que son las implicaciones clave del último? Si pudieras volver a repasar este concepto, ¿qué es lo que harías de forma diferente?...".

Luz-Del-Sol-De-Otoño-Que-Dora-Los-Membrillos se esforzaba en contestar..., ¡pero eso le obligaba a pensar mucho! El Maestro Gin y Seng le interrumpió.

\section{-iHemos descubierto la 'Ley del Periodista'!}

-¡Desde luego! ¡Con tanta pregunta..., parezco una entrevistada! -dijo riendo Luz-Del-Sol-De-OtoñoQue-Dora-Los-Membrillos.

-La mayor parte del éxito de una entrevista está en el entrevistador, no en el entrevistado -matizó el Maestro Gin y Seng, que añadió-: Hay que preguntarse todo. El modo más rápido y directo de estimular la creatividad es formular preguntas. Es como volver a ser niños y usar la palabra favorita del niño: ¿por qué?

-Las preguntas siempre han sido el medio clásico de obtener información de otras personas. Podemos usarlas para obtener información de nosotros mismos o dirigir nuestra búsqueda. Ésta es la base de las llamadas preguntas socráticas. Una pregunta es un instrumento para dirigir la atención. Hay dos tipos de preguntas: preguntas de pesca y preguntas de caza -explicó el Maestro Gin y Seng-. Cuando vamos a pescar ponemos el cebo en el agua y no sabemos lo que vamos a sacar. Una pregunta de pesca puede tener muchas respuestas, es una pregunta abierta: ¿qué, cuáles, cómo...? Sin embargo, en la caza apuntamos a algo en particular. No tiramos al aire esperando a que un pájaro pase por nuestro camino. Las preguntas de caza tienen un objetivo conocido, son preguntas de confirmación. Tenemos una idea sobre algo y deseamos comprobarla. Son preguntas cerradas, se contestan con sí o no. Hacer preguntas con habilidad supone una combinación de preguntas de pesca y de caza.

Y se puso a meditar... « ¿De qué forma inicia el Maestro la cadena de percepción-curiosidad-sabiduría? Mediante preguntas que exijan un pensamiento de alto nivel: preguntas que exijan una búsqueda a fondo para responder. Las preguntas deberían ser "abiertas", pero con eso no basta. La intención de hacer preguntas para buscar la comprensión no es solo la de tener más palabras en las respuestas, sino más profundidad en el pensamiento necesario para producir la respuesta. Las preguntas suscitan una indagación, una búsqueda de conocimiento, de comprensión. Las preguntas conducen a la "perestroika"'. Cuantas más preguntas, más respuestas; constituyen la raíz del cambio cultural, de la innovación, de la exploración, de la creatividad... El modo fundamental de resolver el problema consiste en formular preguntas, porque las respuestas a estas generarán ideas y soluciones. Cuantas más ideas mejor, y para eso cuantas más preguntas mejor».

Y saliendo de su meditación, escribió en la pizarra:

¿Por qué los árboles esconden el esplendor de sus raíces? 